\title{
Limb Malformation Secondary to Maternal Diabetes: A Case at Mother and Children Tertiary Hospital in Cotonou-Benin Republic
}

\author{
Simon Azonbakin ${ }^{*}$, Daniel Sewadouno¹, Maroufou Jules Alao², Anatole Lalèyè1 \\ ${ }^{1}$ Service d'Histologie, Biologie de la reproduction, Cytogénétique et Génétique Médicale, Faculté des Sciences de la Santé, \\ Université d'Abomey-Calavi, Abomey-Calavi, Benin \\ ${ }^{2}$ Service de Pédiatrie, CHU de la Mère et de l'Enfant-Lagune de Cotonou, Cotonou, Benin \\ Email: ^azandeg@yahoo.fr
}

How to cite this paper: Azonbakin, S., Sewadouno, D., Alao, M.J. and Lalèyè, A. (2022) Limb Malformation Secondary to Maternal Diabetes: A Case at Mother and Children Tertiary Hospital in Cotonou-Benin Republic. Open Journal of Pathology, 12, 31-36.

https://doi.org/10.4236/ojpathology.2022.1 $\underline{21004}$

Received: August 26, 2021

Accepted: December 21, 2021

Published: December 24, 2021

Copyright $\odot 2022$ by author(s) and Scientific Research Publishing Inc. This work is licensed under the Creative Commons Attribution International License (CC BY 4.0).

http://creativecommons.org/licenses/by/4.0/

\begin{abstract}
Diabetes in pregnant women could be source of morbidity and mortality if management was not optimal. One of the main complications of diabetes in pregnant women is birth defects. They have an estimated prevalence of $1.5 \%$. They can be isolated or associated to other malformations. Prevention includes systematic screening when monitoring pregnancies, in particular carrying out morphological obstetrical ultrasounds. A case of limb malformation secondary to unbalanced maternal diabetes and absence of prenatal diagnosis despite the high number of ultrasounds that have been performed is reported here. This situation requests more attention to the quality of antenatal ultrasounds caregiving in developing countries.
\end{abstract}

\section{Keywords}

Congenital, Limb Malformation, Diabetes

\section{Introduction}

A malformation is an irreversible defect in the conformation of a tissue, organ, or larger part of the body, resulting from an intrinsic developmental disorder. It is said to be congenital when it was present at birth [1]. Their prevalence is estimated at $1.3 \%$ and $1.9 \%$ of births. They can be isolated or be part of polymalformative syndromes [2] [3]. They often pose diagnostic and therapeutic problems and are associated with high rate of mortality [3]. The aetiology of these malformations is often multifactorial, determined by a set of genetic and environmental factors [4] [5]. The discovery of the various signalling pathways that 
guide normal development of the limb bud and of a number of genes involved, allows us to better understand the genesis of these malformations. Gestational diabetes is associated with an increased risk of birth defects [6] [7] [8] [9]. Prevention includes the control of diabetes and systematic screening during pregnancy monitoring, in particular when performing morphological obstetrical ultrasounds [9] [10]. A case of limb malformation secondary to unbalanced maternal diabetes and absence of prenatal diagnosis is reported here despite the numerous obstetrical ultrasounds that have been performed. This situation requests more attention to the quality of antenatal ultrasounds caregiving in developing countries. Also, this clinical case allows us to sensitize once again diabetic patients to rigorous management during pregnancy.

\section{Observation}

The infant was three months and five days old. He was received at medical genetic consultation for limb and head malformation. He was born from a non-consanguineous marriage and a normal pregnancy. Her mother had undergone six prenatal ultrasounds. The 33-year-old mother had type 1 diabetes discovered 21 years ago. This condition was not adequately treated with no follow up established. She had no history of miscarriage or a family history of malformation. No teratogenic drugs and no exposure to ionizing radiation were recorded. The clinical examination revealed a good general condition, a weight of $3.220 \mathrm{~kg}(-2 \mathrm{DS})$ and a height of $63 \mathrm{~cm}(+0.25 \mathrm{DS})$, a bilateral exophthalmos, a malformation of the right hand with amputation of the last two fingers, an amputation of right and left feet and a right inguinoscrotal hernia (Figures 1-4). There were no other morphological abnormalities at complete physical examination. A karyotype had been performed and was normal. There was no X-Ray examination performed. It was concluded to limb malformation secondary to maternal diabetes when taking into account the abnormalities and the context of unbalanced type 1 maternal diabetes. The multiple localizations of these abnormalities with craniofacial involvement were not in favour of amniotic bands syndrome. Orthopaedic care was offered to facilitate social integration and professional integration in future.

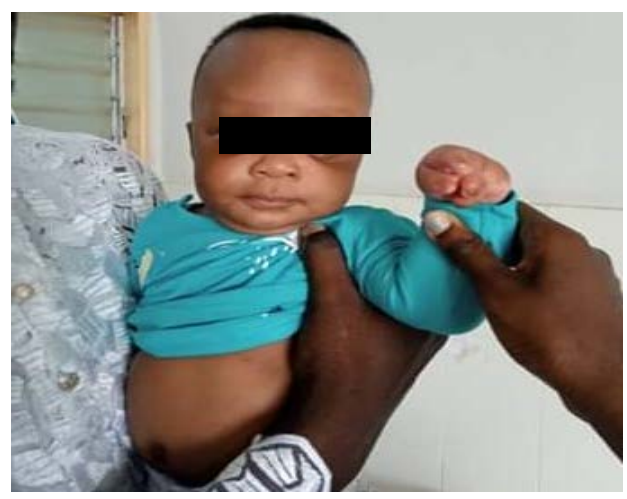

Figure 1. Bilateral exophthalmos. 


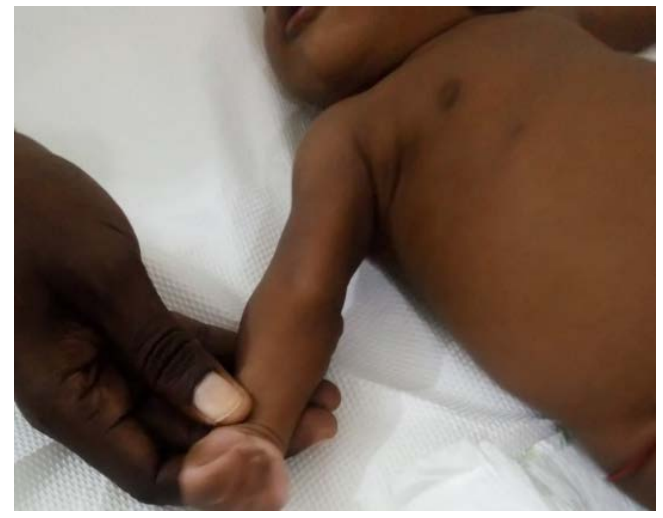

Figure 2. Amputation of the last two fingers of the right hand.

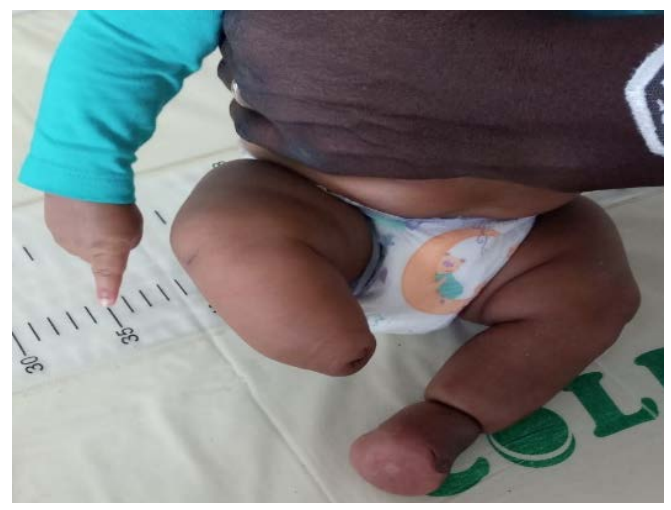

Figure 3. Amputation of two foot.

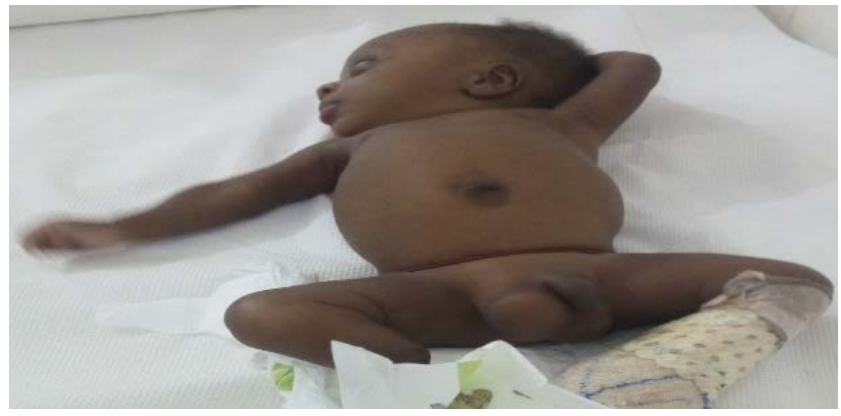

Figure 4. Right inguino-scrotal hernia.

\section{Discussion}

Although most congenital anomalies have no explanation, nearly $10 \%$ of them can be attributed to environmental factors such as maternal pathology, intoxication, drugs and alcohol abuses [2] [3]. Indeed, in a study carried out in Morocco in 2013, it was found that taking drugs such as antiepileptic or plants such as fenugreek was associated with a significant risk of congenital malformation occurrence [4]. Diabetes mellitus is one of the maternal metabolic diseases associated with fetal malformations [1] [3] [10]. Many authors have reported that the abnormalities were predominantly associated with pre-existing diabetes besides gestational diabetes which is tough to be less harmful. Indeed, the establishment 
of the organs and functions of the baby is done during the first eight weeks of development. It is done by induction and progressive differentiation. Damage to one organ could therefore be accompanied by damage to other organs even if they are far away. The role of peri-conceptual maternal hyperglycemia in organogenesis disorders is currently known as well as the mechanisms behind this embryopathy [7] [10] [11] [12]. The rate of malformations is similar for diabetes 1 and diabetes 2 with an increased risk of three to four times compared to the general population [6] [13] [14]. The risk is mainly linked to the teratogenic effect of metabolic disorders, and primarily to maternal hyperglycemia in the first eight weeks of pregnancy [6]. However, the fact that the pelvic limbs are under the influence of several molecular cascades begins in the 4th week of embryonic development. Limb's growth takes place along the proximo-distal axis. In the first weeks, cells in the vicinity of the apical ectoblastic ridge are maintained in a highly proliferative undifferentiated state under the influence of the Fibroblast Growth Factor (FGF) produced by the apical ridge [12]. At the same time, cells that are distant were also exposed to the influence of retinoic acid secreted by the mesenchymal cells of the walls. These two cell populations meet at the level of the differentiation front. Thus during subsequent growth, the proximal cells under the influence of retinoic acid and the expression of different genes differentiate to form the stylopod, the zeugopod and the autopod. The morphogenesis of limb bones is determined by homeobox family genes. The expression of these genes results from the combined action of the SHH, FGF and WNT7a genes which trigger the expression of HOX in three phases corresponding to the future three segments of the limb (stylopod: humerus/femur, zeugopods: Radius/ulna, tibia/fibulla, and autopod: hand/feet). Thus, it should be noted the important role played by the HOX genes. The limb malformations observed in this observation corroborate this pathogenesis. It's about probably in addition to metabolic disorders, a disturbance in the activity of the HOX gene [13]. Amniotic straps can cause constrictions or even limb or finger amputations. These come from adhesions between the amnion and the fetus, or traumatic wounds of the amnion that separate and surround the body of the fetus. In this specific case, the multiple localizations of amputations associated with other anomalies such as inguino-scrotal hernia are not compatible with this hypothesis. Maternal hyperglycemia results in a disruption of the carbohydrate metabolism of the developing embryo with the alteration of various metabolic pathways, such as the polyol pathway, the metabolism of arachidonic acid and prostaglandins, and the excess production of reactive oxygen species [6]. So in this case, a disruption of the molecular signalling of retinoic acid is very likely. In reality, it is a combination of several factors mainly involving hyperglycemia, ketone bodies, oxidative stress in the endoplasmic reticulum, mitochondrial metabolism [6]. Type I diabetes in pregnant women continues to be a major problem in neonatal morbidity and mortality. The case reported here is a typical example of a maternal diabetic imbalance and its harmful consequences on the newborn. These considerations must be fully integrated, both by the ultrasound prescriber and by the sono- 
grapher who takes charge of the specific monitoring of these pregnancies at increased risk of malformation. Thus, we can hope for an undeniable gain in sensitivity [8]. A better quality of sonographers and of the equipment used could have made it possible to recognize this important morphological anomaly. The early discovery of the anomaly could have allowed the parents to make a decision as to whether or not to continue the pregnancy on the one hand and on the other hand to anticipate the psychological shock and the reflection on the alternatives of taking into account charge [4] [10] [14]. However, this observation points to inadequacies in ultrasound monitoring of pregnancies and the need to perform obstetric ultrasounds, especially morphological ultrasounds of the 2nd trimester by qualified professionals [3] [9].

\section{Conclusion}

Pregnancy in diabetic patients is a high risk pregnancy in terms of birth defects. Surveillance of pregnant women, education of young women of childbearing age and monitoring of pregnancies must be done well. Prenatal screening for congenital malformations must be done in order to allow better management, which must begin before pregnancy. Such care requires multidisciplinary collaboration. The case presented here shows the need to perform well obstetric ultrasounds by well-trained professionals, in particular morphological ultrasound.

\section{Funding}

This work was not supported by any grant.

\section{Conflicts of Interest}

The authors declare no conflicts of interest regarding the publication of this paper.

\section{References}

[1] Smith, D.W. (1975) Classification, Nomenclature, and Naming of Morphologic Defects. Journal of Pediatrics, 87, 162-164. https://doi.org/10.1016/S0022-3476(75)80111-9

[2] Forci, K., Alami, M.H., Bouaiti, El A., Slaoui, M., Alaoui, A.M. and Izgua, A.T. (2020) Exploratory Study of Risk Factors for Congenital Malformations in Morocco. https://assets.researchsquare.com/files/rs-39095/v1/39704669-48d6-4eee-a31b-3606f ef35886.pdf? c=1631844802

[3] Alao, M.J., Gbénou, A.S., Diakité, A.A. and Sagbo, G. (2014) Agénésie des avants bras et des jambes: Une malformation rarissisme. Mali Medical, 29, 51-53.

[4] Sabiria, N., Kabiria, M., Razineb, R., Kharbacha, A. and Barkat, A. (2013) Facteurs de risque des malformations congénitales : étude prospective à la maternité Souissi de Rabat au Maroc Congenital malformations risk factors: Prospective study of Rabat Souissi maternity in Morocco. Journal de Pédiatrie et de Puériculture, 26, 198-203. https://doi.org/10.1016/j.jpp.2013.05.001

[5] Kapur, A., Mcintyre, H.D. and Hod, M. (2019) Type 2 Diabetes in Pregnancy. Endocrinology and Metabolism Clinics of North America, 48, 511-531. 
https://doi.org/10.1016/j.ecl.2019.05.009

[6] Eriksson, U.J. and Wentzel, P. (2016) The Status of Diabetic Embryopathy. Upsala Journal of Medical Sciences, 121, 96-112. https://doi.org/10.3109/03009734.2016.1165317

[7] Victoria, M. and Allen, B.A.A. (2007) Tératogénicité associée aux diabètes gestationnel et préexistant. Journal of Obstetrics and Gynaecology Canada, 29, 935-944. https://doi.org/10.1016/S1701-2163(16)32652-4

[8] Potier, A. and Tordjman, L. (2009) Échographie des malformations fotales liées au diabète maternel (hors malformations cardiaques). La Lettre du Gynécologue, 341-342, 25-28.

[9] Kalter, H. (1991) Five-Decade International Trends in the Relation of Perinatal Mortality and Congenital Malformations : Stillbirth and Neonatal Death Compared. International Journal of Epidemiology, 20, 173-179. https://doi.org/10.1093/ije/20.1.173

[10] Aberg, A., Westbom, L. and Källén, B. (2001) Congenital Malformations among Infants Whose Mothers Had Gestational Diabetes or Preexisting Diabetes. Early Human Development, 61, 85-95. https://doi.org/10.1016/S0378-3782(00)00125-0

[11] Yong, H.Y., Shariff, Z.M., Rejali, Z., Nisak, B., Yusof, M., Yasmin, F., et al. (2018) Seremban Cohort Study (SECOST): A Prospective Study of Determinants and Pregnancy Outcomes of Maternal Glycaemia in Malaysia. BMJ Open, 8, e018321. https://doi.org/10.1136/bmjopen-2017-018321

[12] Mitanchez, D., Yzydorczyk, C. and Simeoni, U. (2015) What Neonatal Complications Should the Pediatrician Be Aware of in Case of Maternal Gestational Diabetes? World Journal of Diabetes, 6, 734-743. https://doi.org/10.4239/wjd.v6.i5.734

[13] Langman, J. (2018) Embryologie Médicale. 9ème Edition, Pradel, McGill University, USA.

[14] Mitanchez, D. (2010) Foetal and Neonatal Complications in Gestational Diabetes: Perinatal Mortality, Congenital Malformations, Macrosomia, Shoulder Dystocia, Birth Injuries, Neonatal Complications. Diabetes \&Metabolism, 36, 617-627. https://doi.org/10.1016/j.diabet.2010.11.013 